\title{
El estandarte y el frontal de sant Ot: ¿El ajuar del santo obispo de la catedral de la Seu d'Urgell?*
}

\author{
Laila Monge SIMÉON \\ Universitat Autònoma de Barcelona \\ lailamonge@gmail.com
}

\section{RESUMEN}

El estandarte de sant Ot y el frontal bordado del Victoria and Albert Museum, dos bordados redescubiertos a inicios del siglo XX en la catedral de la Seu d'Urgell, son obras relevantes del románico peninsular al lado, por ejemplo, del famoso Tapiz de la Creación de la catedral de Girona. Ambas piezas precisaban de una revisión histórico-artística para analizar sus vínculos, así como para intentar precisar su lugar de producción, posiblemente un taller local de bordados en un monasterio femenino del entorno de la sede episcopal y bajo la protección de la familia condal. Así, el estandarte y el frontal de altar, creados en relación al reciente culto de la figura de san Ot, se mostrarían conjuntamente en ceremonias litúrgicas concretas en la catedral.

Palabras clave: Seu d'Urgell; cathedral; románico; bordado; seda; frontal de altar; santa Cecília d'Elins; san Ot.

\section{The Banner and the Altar Frontal of Saint Ot: The Grave Goods of the Holy Bishop of the Cathedral of La Seu d'Urgell?}

\begin{abstract}
The banner of saint Ot and the altar frontal of the Victoria and Albert Museum, two embroideries rediscovered at the beginning of the 20th century in the cathedral of la Seu d'Urgell, are two relevant objects of the Spanish Romanesque among, for example, the famous "Creation" tapestry from the Cathedral of Girona. Both objects needed a historical and artistic review to analyse their links, and to narrow down their possible place of production, maybe a local embroidery workshop placed in a women's monastery nearby the episcopal chair and under the protection of the family of the count. So, the banner and the altar frontal, created in relation with the new worship of the figure of saint Ot, were shown together in exceptional events celebrated at the cathedral.
\end{abstract}

Key words: Seu d'Urgell; cathedral; Romanesque; embroidery; silk; altar frontal; Saint Cecília d'Elins; Saint Ot.

\footnotetext{
* La presente contribución se inscribe dentro de los estudios llevados a cabo en el proyecto de investigación Artistas, Patronos y Público. Cataluña y el Mediterráneo (siglos XI-XV) - MAGISTRI CATALONIAE (MICINN - HAR2011-23015). Véase www.magistricataloniae.com
} 
El estudio sobre los bordados medievales en los territorios de la Península Ibérica es una cuestión que se ha resuelto tan solo de forma parcial, debido a que se trata de ejemplares aislados y únicos, afectados por la dispersión de conjuntos y la ausencia de documentación ${ }^{1}$. A pesar de que esta circunstancia pueda dificultar su investigación, sobre todo por la falta de referentes que nos permitan establecer comparaciones dentro de la misma técnica, es preciso revisar las hipótesis ya planteadas y abrir nuevas líneas de investigación ${ }^{2}$.

Los reducidos ejemplos de producción románica que han llegado hasta el día de hoy se concentran en los territorios de los antiguos condados catalanes. Uno de los más antiguos, el bordado de la condesa Guisla del monasterio de Sant Martí del Canigó (Conflent) fechado a principios del siglo XI, si bien actualmente esta cuestión está siendo revisada por Rosa M. Martín i Ros. Probablemente esta pieza serviría de mantel de altar y se encuentra repartida entre el mismo cenobio y el Musée National du Moyen Âge (París). Dentro de esta misma práctica de los ornamentos de altar - a veces también relacionados con los ajuares de los santos venerados y en particular con sus sepulcros - extendida en las iglesias del siglo XI y XII también se creó la estola de sant Narcís de la canónica de Sant Feliu de Girona, conservada aún in situ. Pero la pieza principal dentro de este contexto - conservada por fortuna - es el bordado tradicionalmente conocido como Tapiz de la Creación de la catedral de Girona ${ }^{3}$. Si bien estos testigos materiales son poco numerosos, es significativa la abundante cantidad de menciones de que disfrutan los bordados y otras tipologías textiles en la documentación contemporánea referente a la ornamentación de las iglesias, como pueden ser los inventarios de altares o las dotalías de los templos ${ }^{4}$.

1 MARTÍN i ROS, Rosa M., "La dispersió dels teixits medievals: un patrimoni trossejat", en Lambard. Estudis de l'art medieval, vol. XII, 1999-2000, pp. 165-182.

2 Quisiera expresar mi agradecimiento a Manuel Castiñeiras, Joan Duran-Porta, Lorena García y Laia Pérez por la ayuda y paciencia mostradas durante la preparación de este texto y por las aportaciones que tan amablemente han realizado.

3 Dado la excepcionalidad de la obra, las propuestas historiográficas en relación a este bordado románico singular no habían resultado concluyentes, sobre todo por lo que respecta a su centro de producción. Recientemente, Manuel Castiñeiras ha desarrollado una innovadora hipótesis sobre su posible lugar de producción en CASTIÑEIRAS GONZÁLEZ, Manuel, El Tapiz de la Creación, Girona, Capítol de la Catedral de Girona, 2011.

4 Estas citas han sido abundantemente publicadas. Cabe recordar la exhaustiva publicación de la documentación del Arxiu Capitular de la Seu en diversos números de la revista Urgellia principalmente por Cebrià Baraut referente al obispado de Urgel (BARAUT i OBIOLS, Cebrià, "Els documents (...) de l'Arxiu Capitular de la Seu d'Urgell", en Urgellia, 1, 1978, pp. 11-182, 2, 1979, pp. 7-145, 481-488, 3, 1980, pp. 7-166, 4, 1981, pp. 7-186, 5, 1982, pp. 7-158, 6, 1983, pp. 7-244, 7, 1984-1985, pp. 7-220, 8, 1986-1987, pp. 7-150, 9, 1988-1989, pp. 7-312, 10, 1990-1991, pp. 7-350, 11, 1992-1993, pp. 7-160, 12, 1994-1995, pp. 7-414, 16, 2006-2007, pp. 7-170; MARQUĖS SALA, Benigne, "Els documents de Santa Cecília d'Elins (881-1198)", en Urgellia, $\mathrm{n}^{\circ} 15,2002-2005$, pp. 9-174), o el de Ramon Ordeig i Mata para recopilar las consagraciones y dotalías de iglesias catalanas. Singulares y especialmente interesantes nos resultan las menciones de tejidos en la documentación del monasterio femenino de Sant Joan de les Abadesses (Ripollès), MASDEU, Josep, "Un inventari de 1217 de Sant Joan de les Abadesses", en Butlletí del Centre Excursionista de Vic, $\mathrm{n}^{\circ}$ 21, IV, 19211924, pp. 141-146; MASDÉU, Josep, "Un inventari del Monestir de Sant Joan de les Abadesses", en Butlletí del Centre Excursionista de Vic, $\mathrm{n}^{\circ}$ 2, 1915-1917, pp. 42-45; CRISPÍ CANTÓN, Marta y MONTRAVETA RODRÍGUEZ, Miriam (eds.), El monestir de Sant Joan de les Abadesses, Sant Joan de les Abadesses, 2012. 
A esta lista faltan por añadir dos piezas catalanas que, curiosamente, proceden de un mismo templo: el estandarte de sant Ot y el frontal bordado del Victoria and Albert Museum. Ambos proceden de la catedral de la Seu d'Urgell y son, también, un ejemplo de dispersión que ha dificultado su comprensión.

Este texto abordará el tema de los bordados medievales conservados en la sede episcopal catalana de la Seu d'Urgell y se organizará mediante los puntos siguientes. En primer lugar, se hará una presentación de las dos piezas que nos ocuparan, el frontal bordado de la Seu y el estandarte relacionado tradicionalmente con la figura del obispo Ot o Odón de Urgell. A continuación, se trataran las problemáticas que plantean el estudio de ambos bordados y, por último, se ofrecerá una hipótesis para su datación, función y lugar de producción ${ }^{5}$.

\section{Los bordados de la Seu d'Urgell}

El célebre estandarte ${ }^{6}$ (fig. 1), guardado antiguamente en el relicario del altar de san Ot de la sede urgelitana, ya en 1908 formó parte de la Exposición Hispano-Francesa de Zaragoza, donde llamó la atención de la Junta de Museus de Barcelona ${ }^{7}$. En el año 1918, el organismo catalán adquirió el bordado, trasladándose así a Barcelona. Formó parte de otras exposiciones, como la de Arte Románico de 1961 o la titulada Catalunya medieval de 1992. Actualmente se conserva en el Museu Tèxtil i d'Indumentària de Barcelona ${ }^{8}$.

Con $105 \mathrm{~cm}$ de altura y $69 \mathrm{~cm}$ de ancho, el estandarte consta de una base de lino de color crudo con ligamento de tafetán sobre el que se realizó el bordado mediante punto de figuras ${ }^{9}$ con sedas de poca torsión de color rojo, rosado, amarillo-dorado y

5 La presente comunicación está basada en los resultados del trabajo de fin de máster MONGE, Laila, Els teixits de la catedral de la Seu d'Urgell en època romànica, 2011 [inédito], dirigido por Manuel Castiñeiras y presentado en septiembre de 2011 en la Universitat Autónoma de Barcelona.

6 Los principales estudios realizados sobre esta obra son: FOLCH i TORRES, Joaquim, “L'estendard de Sant Ot", en Anuari de l'Institut d'Estudis Catalans, VI, 1915-1920, pp. 1-7; FOLCH i TORRES, Joaquim, "L'estendard de Sant Ot", en Gaseta de les Arts, n 32, 1925, pp. 1-3, n 33, pp. 4-5; GUDIOL I CUNILL, Josep, Nocions d'arqueologia sagrada catalana, Vic, Impremta Balmesiana, 1931 (1902), p. 269 fig. 308; MARTÍN i ROS, Rosa M., "Penó de Sant Ot", en GUARDIA PONS, Milagros, DALMASES BALAÑA, Núria de y ESPAÑOL BERTRAN, Francesca (dirs.), Catalunya medieval, catálogo de la exposición (Barcelona, 1992), Barcelona, Lunwerg, Generalitat de Catalunya, 1992, pp. 54-55; GUARDIA PONS, Milagros; MANCHO SUÁREZ, Carles, "Consideracions a l'entorn dels teixits brodats catalans de l'Alta Edat Mitjana", en Annals de l'Institut d'Estudis Gironins, n³8, 1996-1997, pp. 1455-1479.

7 Desde inicios del siglo XX, esta institución era la encargada de la salvaguarda y difusión del patrimonio catalán. Por ello, se dedicó a adquirir material que dio pie a la formación del primer museo de arte catalán y otras colecciones. Para más información consultar la monografía GARCIA i SASTRE, Andrea, BORONAT i TRILL, Ma Josep, MARCH, Eva, SALA I TUBERT, Ma Lluisa y TRULLÉN i THOMÀS, Josep Maria, Cent anys de la Junta de Museus, 1907-2007, Barcelona, Publicacions de l'abadia de Montserrat, 2008.

8 N. de inventario 49422, restaurado por el propio Museu Tèxtil i d'Indumentària de Barcelona, se expuso entre 1993 y 2008.

9 El punto de figuras también se conoce como punto de falsa cadeneta y ya se encuentra citado en textos medievales, siendo característico de los bordados románicos - a veces conocidos como opus pictus o pintura a la aguja - . Se trata de una especie de cordoncillo que crea efecto de media cadeneta y visualmente tiene efectos pictóricos. 


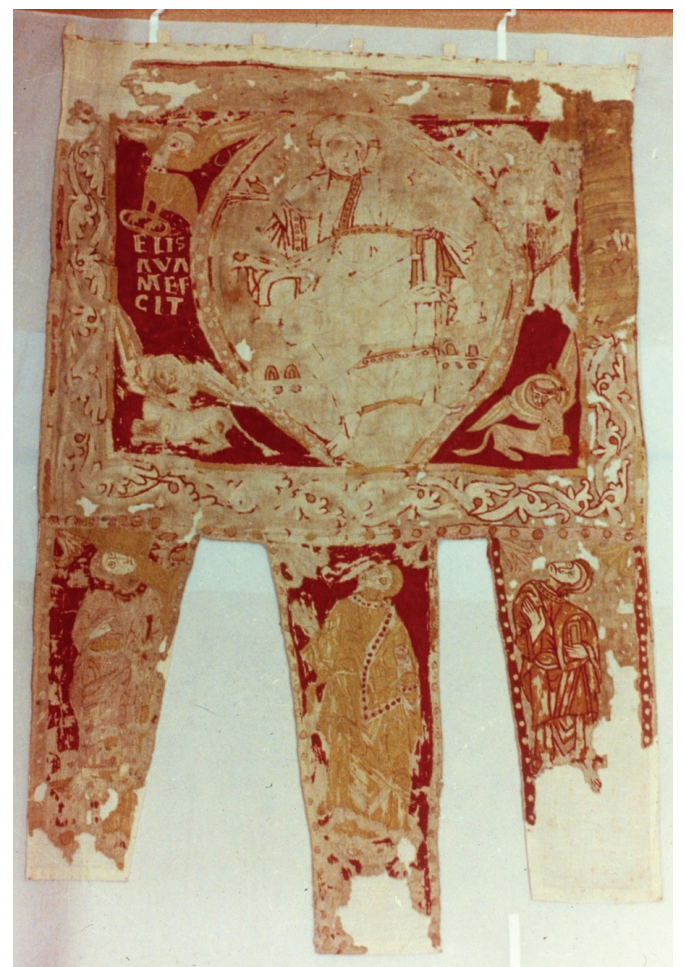

Fig. 1. Estandarte de sant Ot (MTIB 49.422). (C) Col·lecció Disseny Hub Barcelona - Museu Tèxtil i d'Indumentària.

blanco. La pieza está organizada en dos partes, la superior - de forma rectangular - y la inferior que cuelga de la primera, formada por tres gallardetes. La zona superior está encuadrada por una cenefa vegetal y viene presidida por una representación de la Maiestas Domini que sostiene un libro con la mano izquierda y bendice con su diestra, a la vez que sostiene un orbe. La figura divina está enmarcada por una mandorla apuntada, dejando el espacio de las enjutas para incorporar las figuras del Tetramorfos, representadas con su forma animal de cuerpo entero alada. Al lado derecho de Cristo, entre los símbolos de san Juan y san Marcos, encontramos la inscripción ELISAVA ME F(E)CIT. Esta singular leyenda ha sido una de las principales causas del interés que este bordado ha suscitado entre los especialistas, teniendo en cuenta que se trata de la firma de un personaje femenino. Los tres gallardetes de la zona inferior están ocupados, cada uno, por una figura femenina de pie. Las imágenes de los colgantes laterales llevan el libro de los Evangelios y la central un objeto de difícil identificación. Se muestran orantes hacia la imagen superior mediante el gesto de su mano derecha - aunque la mujer de la izquierda parece señalar a Cristo - y la exagerada torsión de sus cabezas. Visten túnica y manto, van descalzas y llevan la cabeza 
cubierta posiblemente con una guimpa ${ }^{10}$. Sobre sus cabezas, hay un lirio en cada esquina del gallardete.

Por lo que se refiere al frontal de altar bordado (fig. 2), se trata de una obra singular que no suele incluirse en los estudios de arte románico en Cataluña ${ }^{11}$, a diferencia del pendón o estandarte. Tenemos conocimiento de su procedencia urgelitana por un comentario del anticuario tolosano Paul Tachard, quien afirmó haberlo comprado en la Seu d'Urgell y vendido posteriormente en el extranjero ${ }^{12}$. La primera cita que nos habla de su localización es del año 1904, cuando el bordado aparece en un catálogo de subasta realizada en Colonia ${ }^{13}$, siendo allí atribuido a una factura alemana del 1200. Por esta razón, pretendiendo complementar su colección de arte germánico, el Victoria \& Albert Museum se hizo con la pieza y la catalogó como procedente de Renania ${ }^{14}$. A pesar de estas anotaciones, aún no se ha podido desvelar el proceso a través del cual el frontal pudo salir de la Seu d'Urgell en los primeros años del siglo $\mathrm{XX}^{15}$.

La pieza (de $65 \mathrm{~cm}$ de altura y $170 \mathrm{~cm}$ de ancho ${ }^{16}$ ) está confeccionada con una base de lino de color crudo, sobre el que se realizó el bordado mediante punto de figuras

10 Parece que la guimpa era una pieza propia del vestuario monacal femenino a partir del siglo XI, a pesar de que su existencia se remonta al siglo IX, según recoge PUIGGARÍ I LLOBET, Josep, Monografia histórica e iconográfica del traje, Barcelona, Librería de Juan y Antonio Bastinos, 1886, pp. 80 y 95. Ya en el primer estudio de la pieza, Folch i Torres creyó conveniente identificar las tres figuras como monjas por llevar la cabeza cubierta con esta ligadura. FOLCH i TORRES, Joaquim (1915), op. cit.

11 Las principales aportaciones sobre esta pieza son: GUDIOL i RICART, Josep (et al.), Cataluña (Arte en España), Barcelona, Seix Barral, 1955, p. 42; ALCOLEA i GIL, Santiago, "Bordados", en Artes decorativas en la España cristiana (Ars Hispaniae, Vol. XX), Madrid, 1958, p. 381, fig. 454; KING, Donald, "Medieval and Renaissance embroidery from Spain", en The Victoria and Albert Museum Yearbook: Number Two, London, Phaidon Press, 1970, pp. 55-64; MARTÍN i ROS, Rosa M., "Frontal brodat de la Seu d'Urgell", en Tortosa $i$ les Terres de l'Ebre. La Llitera i el Baix Cinca. Obra no arquitectònica dispersa i restaurada (Catalunya Romànica, vol. XXVI), Barcelona, Enciclopèdia Catalana, 1997, pp. 425-426; YLLA-CATALÀ, Gemma, "Brodat de la Seu d'Urgell", en CASTIÑEIRAS GONZÁLEZ, Manuel y CAMPS i SÒRIA, Jordi (eds.), El Romànic i la Mediterrània. Catalunya, Toulouse i Pisa (1120-1180), catalogo de la exposición (Museu Nacional d'Art de Catalunya, 29 febrer - 18 maig 2008), Barcelona, 2008, pp. 382-383; BARRAL i ALTET, Xavier, "Tessutti intorno all'altare. A proposito del ricamo del Victoria and Albert Museum di Londra con $\mathrm{i}$ fiumi del Paradiso", en Hortus Artium Medievalum, n 15, 2009, 2, pp. 271-282.

12 KING, Donald (1970), op. cit., p. 63.

13 LEMPERTZ' SÖHNE, H., Collection Bourgeois frères: Katalog der Kunstsachen und Antiquitaten des VI. Bis XIX. Jahrhunderts. Versteigerung zu Köln. Herrn Caspar Bourgeois zu Köln bei J.M.Heberle, (Collection Bourgeois Frères, I), Köln, Köln A.RH., 1904, p. 271 lot 1385.

14 N. inventario 1387-1904.

15 La venta de objetos de arte medieval fue especialmente habitual en el obispado de Urgell durante las primeras décadas del siglo XX, pasando así a formar parte de museos o colecciones privadas. Una visión sintética sobre estos sucesos en el área de la Alta Ribagorza, en CAMPILLO QUINTANA, Jordi, "L'espoli del patrimoni historicoartístic pirinenc al segle XX: l'Alta Ribagorça”, en Ripacurtia, nº 5, 2007, pp. 95-118. Entre estas ventas, las más recordadas son las del coro gótico o de las pinturas murales del ábside de santa Caterina de la catedral. LÁZARO GALDIANO, José, El vandalismo en una catedral, Madrid, La España Moderna, 1925. En este caso, uno de los propios compradores del mueble explica la venta del coro gótico. La exposición que reunió los dispersos fragmentos de las pintura del ábside de santa Caterina: CASTIÑEIRAS GONZÁLEZ, Manuel y VERDAGUER SERRAT, Judit (dirs.), La Princesa sàvia: les pintures de santa Caterina de la Seu d'Urgell, Barcelona, (Museu Nacional d'Art de Catalunya diciembre de 2009 - abril de 2010 - Museu Episcopal de Vic marzo - julio de 2010), Barcelona, Museu Nacional d'Art de Catalunya, 2009.

16 Estas son las medidas actuales, dado que la pieza se conserva fragmentariamente. La parte inferior no conservada debía aumentar unos $20 \mathrm{~cm}$ la altura del frontal. Nuestra propuesta de reconstrucción - realizada 


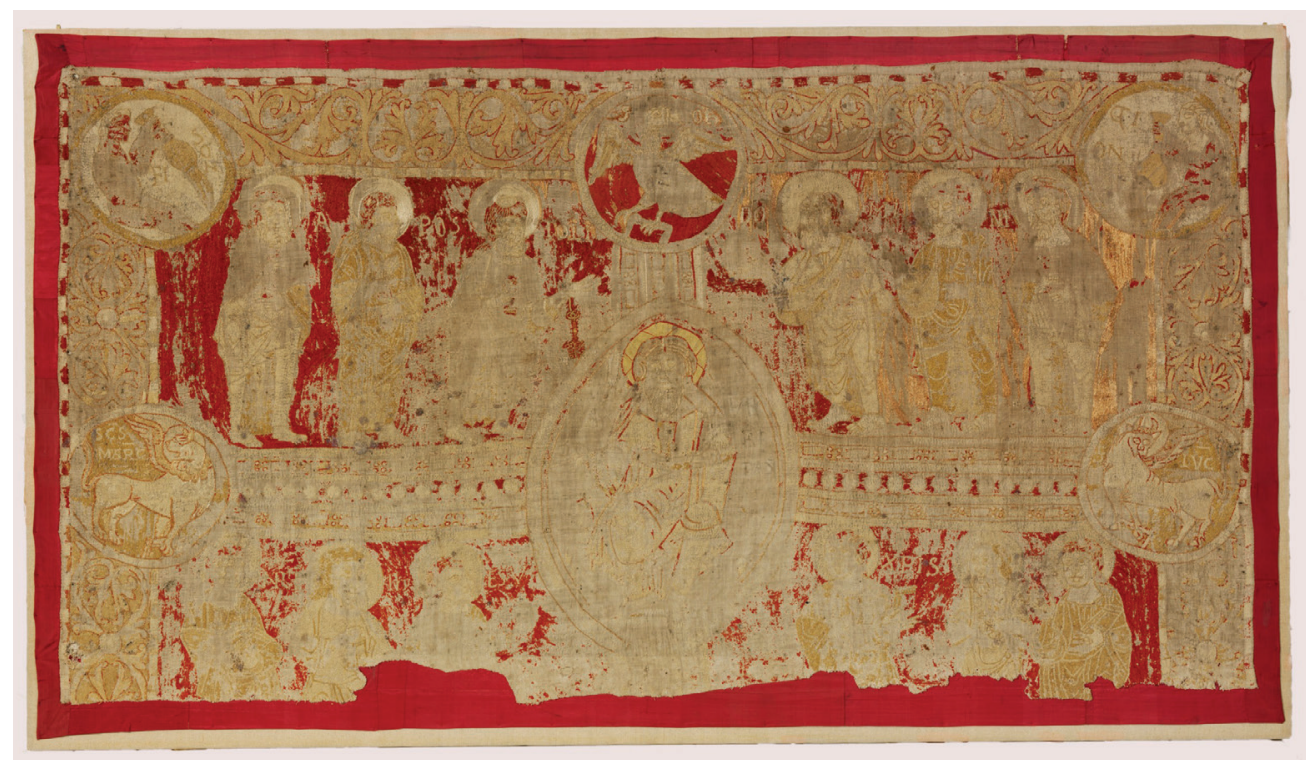

Fig. 2. Frontal bordado (VAM 1387-1904). (C) Victoria and Albert Museum, London.

o falsa cadeneta con sedas de poca torsión de tono rojo, rosado, amarillo y blanco. $\mathrm{Su}$ decoración se ha organizado a través de una cruz gemada, ornada con franjas decorativas perladas. En el centro se presenta Cristo en Majestad dentro de una mandorla apuntada y los brazos de la cruz terminan con medallones que contienen los símbolos del Tetramorfos, de los que solo conservamos tres y van identificados por inscripciones ${ }^{17}$. En las esquinas, siguiendo el mismo sistema de medallones, se han representado las personificaciones de los ríos del Paraíso, entre las que distinguimos las del río Pisón y Geón, también acompañadas de una inscripción ${ }^{18}$, y se han perdido las de los ríos Tigris y Éufrates en los extremos inferiores.

La cruz divide el espacio en dos registros a cada lado, donde se presenta el apostolado organizado en grupos de tres figuras, siempre encaradas hacia Cristo. En el fondo de los compartimentos, a la altura de las cabezas, transcurre una inscripción continua identificativa ${ }^{19}$. El bordado está enmarcado por dos franjas ornamentales, la primera a base de motivos vegetales y la exterior con una cenefa de ajedrezado.

gracias a la iconografía conservada y el principio de simetría - otorgaría a la pieza una altura de $90 \mathrm{~cm}$ aproximadamente, de los que conservamos $65 \mathrm{~cm}$.

17 S(AN)C(TV)S MARC(VS), S(AN)C(TV)S IOH(ANNES), S(AN)C(TV)S LUC(HAS). El medallón inferior que contenía la representación del evangelista Mateo no se conserva.

18 FISON, GION. Se han caracterizado como personajes de cuerpo entero que sostienen un jarrón que emana agua. Posiblemente se habrían individualizado, dado que las dos personificaciones de ríos conservadas presentan las carnaciones de colores distintos. El río Pisón tiene el rostro y el pecho de color rojo y el Geón de color blanco.

19 APOSTOLI DOMINI N(OST)RI IHESV(S) XRISTI. En la franja superior, al lado derecho de Cristo, se ha reconocido a san Pedro, por las llaves y la tonsura. Probablemente, detrás de él estaría san Juan Evangelista 
Estos bordados urgelitanos son unos de los mejores testigos conservados del arte textil en la Cataluña de época románica, como demuestran sus dimensiones y el dominio de la técnica del bordado, así como su bella factura, su figuración y la curiosa inscripción.

La producción de estas dos excepcionales bordaduras se ha vinculado a la catedral de la Seu d'Urgell. La historiografía ha atribuido generalmente la factura de ambos bordados a un mismo taller, pero no se ha conseguido identificar hasta el día de hoy un centro de producción concreto ni, por lo tanto, una posible autoría.

La reciente propuesta sobre el centro de producción de bordados en torno a la catedral de Girona ${ }^{20}$ defiende que la responsable de la factura del extraordinario Tapiz de la Creación fue la comunidad femenina del monasterio benedictino de Sant Daniel de Girona, atribuyendo también a este mismo cenobio la estola de sant Narcís anteriormente citada. Entre los diversos argumentos que se mencionan, cabe destacar el vínculo entre la comunidad monástica y el poder condal, así como su proximidad con el centro catedralicio gerundense. Esta tesis nos ofrece la posibilidad de desarrollar una argumentación análoga para las dos piezas urgelitanas, puesto que parece sugerente plantear unos nexos similares en torno al centro catedralicio de la Seu d'Urgell ${ }^{21}$. En este sentido, cabe contemplar una hipótesis en que la producción de dichas obras se efectuara en un monasterio femenino vinculado a la sede episcopal, admitiendo tan solo como posibilidad el cenobio de Santa Cecília d'Elins, que fue el mayor y prácticamente el único monasterio femenino en toda el área del obispado de Urgell, al menos hasta mediados del siglo XII.

\section{Una hipótesis sobre la producción de los bordados: Santa Cecília d'Elins}

El monasterio benedictino de Santa Cecília d'Elins (Alt Urgell) ha generado poca atención por parte de los estudiosos. Situado en las cercanías de la Seu d'Urgell, a unos $20 \mathrm{~km}$, los muros del edificio que conformaba la antigua iglesia han sido reaprovechados y actualmente forman parte de una finca particular conocida como "lo Monestir" 22 . Se fundó en el año 881 , siendo entonces habitado por una comunidad masculina. En el año 1078, esta se sustituyó por un grupo de monjas benedictinas procedentes del monasterio femenino barcelonés de Sant Pere de les Puel·les, hecho que cambió radicalmente la historia de la abadía, convirtiéndola de esta manera en

imberbe y san Andrés con barba larga. Y al lado izquierdo de Cristo san Pablo, este ya dudoso.

20 CASTIÑEIRAS GONZÁLEZ, Manuel (2011), op. cit.

21 La posibilidad de que tanto el estandarte como el frontal hubieran sido producidos en un mismo taller del entorno de la catedral urgelitana ya fue sugerida por Rosa M. MARTIN i ROS. Vid. MARTIN i ROS, Rosa M. (1997), op. cit., p. 426.

22 Por desgracia, los elementos constructivos conservados del monasterio son muy escasos y no ayudan a conocer mejor su historia. La documentación nos explica que la iglesia tenia tres altares dedicados a tres santas: el principal estaba dedicado a santa Cecília, la titular del cenobio; mientras que los laterales a santa María y santa Fe. ADELL i GISBERT, Joan Albert, CASES i LOSCOS, Maria Lluïsa, "Santa Cecília d'Elins", en l'Alt Urgell. Andorra. Catalunya Romànica, VI, Barcelona, Enciclopèdia Catalana, 1992, pp. 237-242. 
el único cenobio femenino de todo el obispado de Urgell ${ }^{23}$. La relación entre ambas comunidades se constata mediante el hecho de que la abadesa Eliarda de Sant Pere de les Puel·les rigió el cenobio de Elins durante los primeros años después de la conversión ${ }^{24}$.

La proximidad de este centro a la Seu d'Urgell permitió que se establecieran relaciones tanto con la casa condal de Urgell como con la sede episcopal. El vínculo con la familia condal está documentado, desde el nacimiento del cenobio, a través de donaciones ${ }^{25} \mathrm{o}$ de ingresos de jóvenes de la misma familia, que llegaban acompañadas de una dote que representaba una fuente de ingresos para la comunidad ${ }^{26}$.

En la segunda mitad del siglo XI, y en particular entre 1060 y 1080, el conde Ermengol IV de Urgell y su esposa Llúcia tuvieron un papel importante en los sucesos clave de Santa Cecília. Realizaron cuantiosas donaciones y fueron los principales impulsores de la reforma del año 1078. Solicitaron directamente a Amat de Oloron, legado pontificio de Gregorio VII, que sustituyera los monjes de Elins por una comunidad femenina y el 6 de enero de 1080 hicieron una importante dotación al cenobio con el objetivo de ayudar a la nueva comunidad benedictina instalada en el monasterio. A finales del mismo año 1080, los condes, con el soporte de la abadesa Eliarda, solicitaron al obispo Bernat Guillem que presidiera la consagración de la iglesia de Santa Cecília. Conviene remarcar que en el acta de esta ceremonia se menciona a la condesa Llúcia "procuratrix ac gubernatrix illius loci benignisima", considerándola una figura importante vinculada con el monasterio ${ }^{27}$.

También la condesa Llúcia de la Marca ${ }^{28}$, madre del obispo Ot de Urgell, gran promotora artística vinculada al cenobio de Sant Pere del Burgal, estuvo relacionada con el monasterio de Santa Cecília d'Elins. Gracias a la documentación, sabemos que también tuvo gestos a favor de Elins entre los años 1083 y $1085^{29}$. Estos favores y aportaciones condales a los monasterios y a la Iglesia solían realizarse con un fin devocional a través de donaciones de bienes inmuebles y rentas, así como de la

23 CABRÉ i PAIRET, Montserrat, "La comunitat de Santa Cecília d'Elins segles XI i XII", en RIU, Manel (coord.), Temps de monestirs. Els monestirs catalans entorn l'any mil, Barcelona, Ed. Pòrtic, 1999, pp. 122125; MARQUÈS SALAS, Benigne (2002), op. cit.; BARAUT i OBIOLS, Cebrià (2006-2007), op. cit. .

24 Benigne Marquès dice que ejerció de abadesa de Santa Cecília como mucho los primeros 5 años, MARQUĖS SALA, Benigne (2002-2005), op. cit.. Entre los años 1167 y 1170, el papa Alejandro III redactó una bula dirigida a la abadesa Valencia de Sant Pere de les Puel-Les, a petición del mismo monasterio barcelonès, donde se confirma la sujeción de Santa Cecília a este (Arxiu Sant Pere de les Puel·les).

25 Aparecen citadas las condesas. Por ejemplo, el año 952 Adelaida hizo una donación para el alma de su difunto marido, el conde Sunifred II, MARQUES SALA, Benigne (2002), op . cit., p. 60.

26 En Santa Cecília d'Elins conservamos tres documentos de este tipo (MARQUÈS SALA, Benigne (2002), op. cit., pp. 58, 75 y 82).

27 MARQUES SALA, Benigne (2002), op. cit., p. 50.

28 No confundir esta condesa con Llúcia d'Urgell, aunque algunos especialistas han visto en Llúcia d'Urgell y Llúcia de la Marca a una sola persona. Esta tesis ha sido rebatida por Martí Aurell. En este caso, Llúcia de la Marca se casó con el conde Artau I de Pallars y era hermana de Almodis de la Marca, mujer de Ramon Berenguer I conde de Barcelona. AURELL i CARDONA, Martí, "Jalons pour une enquete sur les strategies matrimoniales des comtes catalans (IXe-XIe s.)", en Symposium Internacional sobre els orígens de Catalunya (Segles VIII-IX): I, (Barcelona, 1991), vol. 23, Barcelona, Memorias de la Real Academia de Buenas Letras de Barcelona, pp. 281-364, especialmente pp. 326-329 y 361.

29 MARQUĖS SALA, Benigne (2002), op. cit., pp. 53 y 56. 
comitencia de objetos litúrgicos. Sabemos que tanto la orfebrería como los tejidos eran los objetos más valorados de los tesoros de las catedrales, monasterios e iglesias románicas. Por esto, es razonable - y significativo a la vez - que la comitencia privada en este período dejara constancia de su aportación precisamente en las piezas más costosas y delicadas.

Sería probable que Santa Cecília d'Elins albergara un taller de producción de bordados por diversas razones. Principalmente, por su calidad de monasterio femenino. Esta relación ha sido ya resaltada en otras obras textiles, gracias a las inscripciones que constan a veces en este tipo de producciones. En estas leyendas, suelen materializarse nombres de mujeres que se atribuyen la factura de las mismas obras, esperando que se relacione así su nombre con la pieza en cuestión. Si bien es preciso un estudio específico en cada caso, el panorama general demuestra la existencia de una relación entre el monacato femenino y la técnica del bordado en estas fechas ${ }^{30}$. Este es el caso del tapiz de Colonia de Ragenardus, donde se ha inscrito GERBERGA ME FECIT, llevando a identificar este nombre con la mujer del conde. Por otra parte, ya en el campo religioso, la estola de sant Narcís de Sant Feliu de Girona, donde leemos MARIA ME FECIT, se ha querido atribuir a una monja del monasterio de Sant Daniel. Por supuesto, la actividad textil de las monjas tomaba como modelo la figura de la Virgen María, paradigma de la doncella bordadora y referente del tipo de vida de estas comunidades. Este hecho lo recoge la fuente apócrifa, ampliamente difundida, del Protoevangelio de Santiago ${ }^{31}$. Así, vemos como en la Virgen representada en la estola de sant Narcís se ha resaltado su caracterización monacal. Este aspecto acentúa la condición religiosa de las figuras que firmaban estos bordados.

Los estudios de los centros productores de bordados corroboran la especialización de estos talleres monásticos, por lo que cabe resaltar que las monjas conocían perfectamente los procesos de elaboración de estas obras textiles ${ }^{32}$. En este sentido, la historiografía anglosajona ha investigado detenidamente la organización de las distintas fases que comportaba la producción de bordados y ha prestado atención a la figura del dibujante de cartones. Se ha comprobado que existen ciertos vínculos entre el ámbito textil y las páginas iluminadas de los códices, lo que nos hace pensar que la concepción de estas piezas sería producto de la participación de miniaturistas o pintores ${ }^{33}$.

30 CASTIÑEIRAS GONZÁLEZ, Manuel (2011), op. cit., pp. 36-40; GREENUP, Sylvia, “Mabel: l'arte del ricamo in Inghilterra", en CASTELNUOVO, Enrico (dir.). Artifex bonus. Il mondo dell'artista medievale, Roma, Laterza, 2004, pp. 129-137, más concretamente p. 132; vid. también: NÍ GHRÁDAIGH, Jenifer, "Mere Embroiderers? Women and Art in Early Medieval Ireland”, en Visualing the Middle Ages, Leiden, 2012, vol. I, pp.93-127. MARIAUX, Pierre Alain, "Women in the Making: Early Medieval Signatures and Artists' Portraits (9th-12th C.)", en MARTIN, Therese (ed.), Reassessing the Roles of Women as "Makers" of Medieval Art and Architecture, Leiden, 2012, pp. 393-427.

31 CASTIÑEIRAS GONZÁLEZ, Manuel (2011), op. cit., p. 39. El Protoevangelio de Santiago explica que, entre las vírgenes de la tribu de David, se encargó a María que ella misma bordara el velo del templo de Jerusalén, que debía "bordar el oro, el jacinto, el amianto, la seda, el lino fino, la verdadera escarlata y la verdadera púrpura" (Protoevangelio de Santiago 10, 2).

32 CASTIÑEIRAS GONZÁLEZ, Manuel (2011), op. cit., p. 39.

33 STANILAND, Kay, Bordadores, London, British Museum Press, 1991, pp. 19 y 22; GREENUP, Sylvia (2004), op. cit., p. 136; CABRERA LAFUENTE, Ana, DEL EGIDO RODRÍGUEZ, Marián, PARTEARROYO LACABA, Cristina, BORREGO DÍAZ, Pilar, GAYO GARCIA, María Dolores, ARTEAGA RODRÍGUEZ, 
El hipotético taller de bordados de Santa Cecília se vincula con el frontal y el estandarte de sant $\mathrm{Ot}$ a través de la inscripción de este segundo, ELISAVA ME F(E) CIT, que pudiese revestirse de un doble sentido. Parece ser que, aquí, una mujer llamada Elisava pretende adjudicarse la factura o comitencia del bordado. Ignoramos, no obstante, su exacta identidad. Bien es verdad que, en otros casos, como en las pinturas del ábside de Sant Pere de Burgal (ca. 1100), ha sido posible identificar la figura femenina representada junto a una inscripción, como la condesa Llúcia de la Marca, a la cual se le rendiría con su efigie un homenaje póstumo ${ }^{34}$. Por el contrario, en nuestro caso, por falta de referencias más cercanas, nos mantenemos en el campo de la hipótesis. El nombre de Elisava, que corresponde al nombre genérico de Elisabet y, por lo tanto, Isabel ${ }^{35}$, aparece referenciado en la Seu d'Urgell en dos documentos, lo que constata - aunque sean de cronologías anteriores - la presencia de este antropónimo en la zona ${ }^{36}$. No podemos descartar, aunque tampoco hay forma de afirmarlo, que Elisava fuera también miembro de la familia condal, por la importancia que tuvo, ya fuera en relación a la factura o la comitencia, la creación de una obra como el estandarte.

Lo que parece clave para un correcto análisis del pendón es la identificación de las tres figuras de los gallardetes que, como ya hizo Folch i Torres, cabría relacionar con monjas. Si bien ninguna de las menciones documentales conservadas de Elisava corresponde a una religiosa, cabe recordar que cuando las mujeres pasaban a formar parte de una comunidad monástica solían adquirir un nuevo nombre que marcaba el inicio de su nueva vida dedicada a Dios ${ }^{37}$. La vida contemplativa de los cenobios se complementaba a veces con actividades que propiciaban la reflexión, como podía ser el bordar, considerada una actividad muy meticulosa que requería mucha habilidad y que acompañaba la meditación diaria. De esta forma, se ha visto también a las monjas bordadoras como creadoras de obras pías. Muchas veces, ellas eran las encargadas de hilar o bordar las vestiduras o piezas del ajuar de los santos, a la vez que recitaban

Ángela y CULUBRET WORMS, Bárbara, “Tejidos Hispanomusulmanes”, en Bienes culturales. Revista del Instituto de Patrimonio Cultural de España, $\mathrm{n}^{\circ} 5$, 2005, p. 37. Esto ocurre en el caso de la bordadora Ethelwynn, que convocó al miniaturista Dunstan en motivo del diseño de un bordado, según un relato del siglo X: CASTIÑEIRAS GONZÁLEZ, Manuel (2011), op. cit., p. 40.

34 CASTIÑEIRAS GONZÁLEZ, Manuel, "La pintura mural", en CASTIÑEIRAS GONZÁLEZ, Manuel y CAMPS SÒRIA, Jordi, El Romànic a les col-leccions del MNAC, Barcelona, Lunwerg, 2008, p. 66.

35 GUARDIA PONS, Milagros y MANCHO i SUÁREZ, Carles (1996-1997), op. cit., p. 1473; AINAUD de LASARTE, Joan, La pintura catalana. La fascinació del romànic, Barcelona, Skira, 1989, p. 38. Con este nombre aparece citada Elisabet, una hermana de Ermengol IV de Urgell que se casó con el rey Sancho Ramírez de Aragón y, más tarde, el año 1080, se volvió a casar con Guillem Ramon conde de Cerdanya. O Elisabet Sibil·la, hija del conde Ermengol VI de Urgell. AURELL i CARDONA, Martí (1991), op. cit., vol. 23, pp. 281-364. La cronología de estas mujeres nos obliga a descartar por completo la posibilidad de que fueran posibles promotoras de los bordados.

36 Fechados en 1018 y 1030. En un caso se trata de Elisaua, mujer de un juez que compra unas propiedades en el condado de la Cerdanya (BARAUT, Cebrià (1981), op. cit., p. 354) y, en el otro, la hija de una mujer a la cual se hace una donación de alodios en el condado de Urgell (BARAUT i OBIOLS, Cebrià (1981), op. cit., p. 438).

37 Existiendo así la posibilidad de que se tratara del nombre de religión de una mujer de la familia condal que conozcamos pero que no aparezca citada (con ese nombre) en la documentación conservada, dado que asumiría este nombre a posteriori, a consecuencia de su entrada en el cenobio. 
textos sagrados, para así envolver los cuerpos venerados con cobertores de la dignidad del personaje. Estas comunidades también producían cortinas u ornamentos para los altares de las iglesias cristianas ${ }^{38}$.

En los textos bíblicos o apócrifos, aparte de María, ya citada como modelo de bordadora, también se encuentra mencionada su prima Isabel. Según el Protoevangelio de Santiago, cuando María acabó su bordado y lo hubo entregado - recibiendo elogios por el trabajo realizado -, se dirigió hacia casa de Isabel. El texto dice que “(María) llamó a la puerta. E Isabel, habiéndola oído, dejó su escarlata, corrió a la puerta, y abrió." (Protoevangelio de Santiago 12,2) ${ }^{39}$. Volviendo a la inscripción de nuestro pendón, sería posible que la Elisava que firma y quizás se representa en el estandarte de sant $O t$ fuera una monja que habría tomado este nombre en iniciar su vida religiosa.

Además de la tradicional lectura de la comitente-bordadora en la leyenda ELIS/ AVA ME F(E)/CIT podemos deducir, en segundo lugar, a partir del signo de abreviación $^{40}$ que figura sobre el nombre una segunda hipótesis más especulativa ${ }^{41}$ (fig. 3). De hecho, la firma se dispone en vertical, dividiendo las palabras de una manera muy particular: en el primer segmento aparece (ELIS) con el signo de abreviación, al que si añadiéramos una $n$ resultaría ser ELINS, creando una evidente relación entre la comitente y el lugar de producción, habiendo hecho coincidir, además, en una misma palabra estos dos conceptos. Algo similar ocurre en AVA, que podría hacer referencia a AVA(TISSA), la abadesa del lugar ${ }^{42}$. Esta asociación podría producirse a pesar de que no haya ningún signo de abreviatura, dado que esta abreviación es corriente, si bien es cierto que la abreviación habitual de abatissa es $\mathrm{ABA}^{43}$.

De ser cierta esta sugerente idea, la inscripción permitiría relacionar efectivamente la producción del estandarte $\mathrm{y}$, posiblemente, también del frontal con el monasterio

38 CASTIÑEIRAS GONZÁLEZ, Manuel (2011), op. cit., pp. 36-40; GREENUP, Sylvia (2004), op. cit., p. 132.

39 Respeto al nombre de Isabel, es curioso que las monjas que ingresaron en Sant Joan de les Abadesses (Ripollès) en el siglo XI tuvieran el apelativo de Elisabets: RIU, Manuel, "Posesiones de monasterio de Sant Joan de les Abadesses en el obispado de Urgell" en Annals de l'Institut d'Estudis Gironins, 1974, vol. 22, pp. 1-9. En relación a este monasterio ripollés, es interesante tener en cuenta que los condes Guifré el Pelós y Riquilda colaboraran en la dotación de este centro, la primera fundación monástica femenina documentada en Cataluña (por lo que vemos una situación similar a la de Santa Cecília d'Elins). O también, fuera de nuestras fronteras, que la bordadora del rey de Inglaterra Enrique III a mediados del siglo XIII fuera una monja benedictina - posiblemente originaria de la abadía de Bury St. Edmunds - llamada Mabel. Distintos documentos citan a esta bordadora y sus encargos, desde una casulla hasta un estandarte: GREENUP, Sylvia (2004), op. cit., pp. 129-130.

40 Este último apunte cabría comprobarlo viendo el reverso del estandarte, por ahora conservado en las reservas del Museu Tèxtil i d'Indumentària de Barcelona. La tendencia a reducir las inscripciones es omnipresente en las obras de arte de época románica, llegando al punto de abusar de esta práctica, y una de las letras que se obvia frecuentemente es la $n$.

41 La abreviación era recurrente en la epigrafía medieval, como recoge con casos concretos FAVREAU, Robert, "Rex, Lex, Lux, Pax. Jeux de mots et jeux de lettres dans les inscriptions médiévales", en Mélanges, Bibliothèque de l'École des chartes, t. 161, 2003, pp. 625-635.

42 Por lo que se podría leer: ELIS/ AVA(TISSA)/ ME F(E)/CIT.

43 Sobre el uso de abreviaturas en las inscripciones medievales catalanas: SANTIAGO FERNÁNDEZ, Javier de, La Epigrafía latina medieval en los condados catalanes (815-circ. 1150), Madrid, A.C. Castellum, 2003, pp. 112-120. 


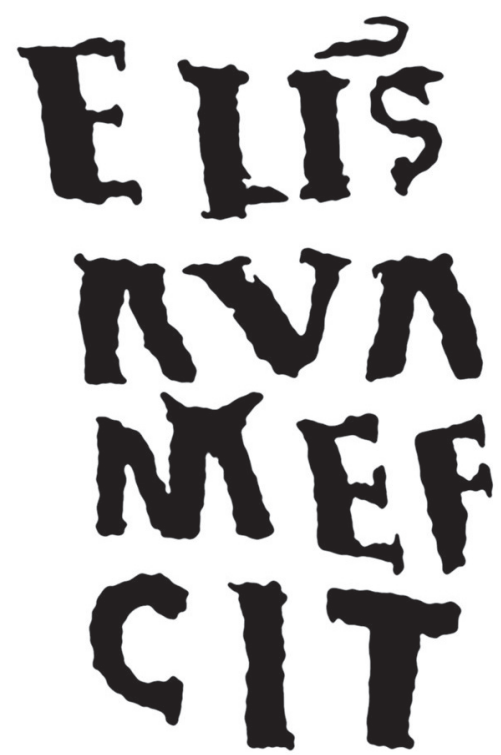

Fig. 3. Inscripción del estandarte de sant Ot (MTIB 49.422). (C) Laila Monge.

de Santa Cecília d'Elins, donde su comunidad femenina se dedicaría a hilar y bordar $y$, según parece, querría figurar en la representación del pendón ${ }^{44}$.

Por último, sería interesante señalar las posibles relaciones que se establecen entre el cenobio de Elins y la sede episcopal. El estudio de piezas de otras disciplinas fechadas entre 1120 y 1140 como las pinturas del ábside de Sant Pere de la Seu, o los frontales de la Seu d'Urgell o dels Apòstols y de Ix (MNAC 15803, 15802) ha permitido apuntar la posibilidad que fuera en estos talleres dependientes de la sede donde se produjeran los muebles para las parroquias o iglesias de sus dominios ${ }^{45}$. Un acercamiento similar permitiría explorar igualmente la posibilidad de que sea el mismo taller episcopal quien realizara los cartones de los dos bordados ${ }^{46}$. Las similitudes entre las citadas obras atribuidas a los talleres catedralicios y los bordados permiten reconocer, también en los segundos, una figuración surgida de un centro intelectual

\footnotetext{
44 Una leyenda tardía parece aludir al lazo entre la comunidad de Santa Cecília de Elins y los tejidos. Los habitantes del Valle de Elins no querían habitar en la masía llamada "Lo Monestí" porque por las noches no se "podia dormir desvelada por el fru-fru incesante de las sedas de las faldas de las monjas" que habían ocupado el cenobio tiempo atrás: COROMINES i VIGNEAUX, Joan, Onomasticon Cataloniae, vol II, Barcelona, Curial, 1994, p. 143.

45 Para obtener una breve síntesis de las obras de pintura sobre tabla que salieron del obrador urgelitano, ver CASTIÑEIRAS GONZÁLEZ, Manuel, "Entorn als orígens de la pintura romànica sobre taula a Catalunya: els frontals d'Urgell, Ix, Esquius i Planès”, en Butlletí Museu Nacional d'Art de Catalunya, nº 9, 2008, pp. 9-41.

46 Como ya hemos visto que está documentado en Inglaterra, igual que la participación de miniaturistas como dibujantes de cartones: GREENUP, Sylvia (2004), op. cit.
} 
importante como eran entonces las catedrales y sus respectivos scriptoria $^{47}$. La introducción de elementos como las personificaciones de los ríos del Paraíso es significativa, puesto que son motivos que aparecen tan solo puntualmente y que no se han incorporado en las representaciones de otros frontales de altar. Asimismo, la singular forma de representarlas - personajes de cuerpo entero con un jarón del que emana agua -, que entronca con una tradición propia de la Antigüedad, como ocurre en el Tapiz de la Creación de Girona, en unos capiteles del monasterio de Notre-Dame la Daurade de Toulouse, en unos capiteles del claustro de la catedral románica de Pamplona o en el arca de las reliquias de san Juan Bautista y san Pelayo de San Isidoro de León ${ }^{48}$. Otro rasgo que refleja la cultura humanística catedralicia es la introducción de inscripciones en ambos bordados, rasgo también presente en frontales y pinturas murales. Estas observaciones permiten asegurar que los responsables del diseño del programa figurativo de las piezas fueron eclesiásticos de sólida formación intelectual, vinculados muy probablemente al centro catedralicio. Probablemente, los conocimientos específicos sobre la técnica del bordado y las materias primas llegarían hasta la Seu d'Urgell mediante estos mismos vínculos.

Para finalizar este breve estudio, nos adentramos en el planteamiento del contexto en que se debieron promocionar estos dos bordados. Para ello, es importante el papel de los obispos sucesivos de la diócesis de Urgell. Precisamente, la voluntad reformista promovida desde Roma a partir de la segunda mitad del siglo XI se tradujo en la participación de los legados pontificios en las distintas diócesis, escogiendo normalmente la sede gerundense para celebrar sínodos que pusieran orden en los territorios de los condados catalanes ${ }^{49}$.

El obispo Ot (1095-1122) fue uno de los máximos defensores de la Reforma en el área catalana. Hijo de los condes Artau I de Pallars y Llúcia de la Marca, nació aproximadamente entre 1063 y 1065 . Fue escogido obispo por unanimidad, según se relata, para ocupar la cátedra episcopal y su actividad evangelizadora fue reconocida inmediatamente ${ }^{50}$. De entre todas las noticias que tenemos de su vida, la más relevante es el impulso de la construcción de una nueva catedral. Los documentos nos informan que alrededor de 1116 Ot redactó una misiva dirigida a los fieles, pidiéndoles expresamente que colaborasen para reformarla. Parece que esta solicitud fue

47 Esta plausible relación ya la propuso Rosa M. Martin i Ros: MARTIN i ROS, Rosa M. (1992), op. cit., p. 358 .

48 ARAGONÉS ESTELLA, María Esperanza, "El capitel de los ríos del paraíso en el claustro románico de la catedral de Pamplona”, en Revisión del Arte Medieval en Euskal Herria, Cuad. Secc. Artes Plást. Monum., $n^{\circ} 15,1996$, pp. 285-296.

49 Amat de Oloron, legado de Gregorio VII, presidió el segundo de estos concilios en el año 1077/1078 en Girona. A pesar de responder a una demanda directa de los condes de Urgell, fue gracias a la intervención de Amat de Oloron que se llevó a cabo la reforma de 1078 del monasterio de Elins, sometiéndolo de esta manera a la reforma gregoriana que también afectó a la diócesis de Urgell. CASTIÑEIRAS GONZÁLEZ, Manuel (2011), op. cit., p. 89; GRAU QUIROGA, Núria, Roda de Isábena en los siglos X-XIII. La documentación episcopal y del cabildo catedralicio, Zaragoza, Institución Fernando el Católico, 2010, p. 64.

50 ALBERT i CORP, Esteve, Sant Ot, bisbe d'Urgell, i la seva època, Barcelona, Rafael Dalmau Editor, 1979; MARQUÈS i PLANAGUMÀ, Josep Maria, "Sant Ot”, en Diccionari d'Història Eclesiàstica de Catalunya, vol. II, Barcelona, Ed. Claret, 2000, pp. 171-172; BESERAN i RAMON, Pere y ADELL i GISBERT, J. Albert, La Catedral de la Seu d'Urgell, Manresa, Angle, 2000, p. 67. 
bien recibida, puesto que el Liber Dotaliorum Ecclesiae Urgellensis recoge múltiples donaciones ad opera a partir de entonces. También consiguió, gracias a las buenas relaciones que mantuvo con el papa Urbano II, una bula que delimitaba y confirmaba las posesiones del obispado.

Cuando el obispo Ot murió en el año 1122 fue sepultado en la catedral, en un arca hecha para la ocasión ${ }^{51}$. Parece que su fama aumentó una vez hubo traspasado y se le rindió devoción popular en la Seu d'Urgell. Tan solo once años más tarde se llevó a cabo su canonización, dedicándosele un altar situado en el primer tramo del transepto meridional, es decir, a los pies del templo ${ }^{52}$ (fig. 4), y se estableció la festividad del santo el día 30 de junio coincidiendo con el aniversario de su traspaso ${ }^{53}$. La devoción por este santo no se extendió mucho geográficamente. Un lugar cercano donde su culto se mantuvo vivo fue en el monasterio de Santa Maria de Gerri, del cual había sido abad en sus últimos años de vida, pero en la Seu d'Urgell también ha pervivido con el paso de los siglos, conservando distintos comentarios que nos explican la confianza que los urgelitanos depositaban en sus patrones san Ermengol y san $\mathrm{Ot}^{54}$.

El sucesor del santo obispo fue Pere Berenguer (1123-1141), quién hizo donaciones a favor de la iglesia y la canónica de Urgell, mientras las obras de la catedral que había iniciado su predecesor proseguían. Reclamó propiedades y privilegios de la sede urgelitana, como al conde de Barcelona Ramón Berenguer III el Grande, y también recibió distintas donaciones, entre otros del conde Ermengol VI de Urgell - nieto de Ermengol IV - en el testamento que hizo al emprender un viaje a Castilla en el año $1133^{55}$. Pere Berenguer promovió en 1133 la canonización de su antecesor, sumando así un tercer santo al episcopologio urgelitano, que contaba ya con san Justo - obispo del siglo VI - y por supuesto con san Ermengol, figura en cierto modo paralela a la de Ot en la primera mitad del siglo $\mathrm{XI}^{56}$.

Un caso bastante próximo geográficamente es el de la antigua catedral de Roda de Isábena y su obispo Ramón Guillermo o Ramón de Roda (1104-1126), el cual vivió coetáneamente al prelado urgelitano. Fue escogido para este cargo en la diócesis

51 FOLCH i TORRES, Joaquim (1915), op. cit., p. 1; COY COTONAT, Agustín, Sort i la comarca de la Noguera Pallaresa, Barcelona, Impr. la Vda. de José Cunill, 1906, p. 268.

52 Ubicación que se mantuvo hasta 1575 , fecha en que se reorganizaron las dedicaciones de la cabecera, trasladando así el altar de san Ot a la capilla sur más cercana al altar mayor. BESERAN, Pere y ADELL, J. Albert, La Catedral de la Seu d'Urgell, Manresa, Angle, 2000, pp. 188 y 204. Antes, sus reliquias fueron expuestas para la veneración pública "Oberta la caixa, en trovaren, a dintre, una altra de més petita en la qual es guardaven els ossos enters del sant baró, amb la vestimenta sagrada amb què, segons costum de cristians, havia estat enterrat. En la primera caixa hi havia terra treta del seu sepulcre $i$ embolicada amb roba" (FOLCH i TORRES, Joaquim (1915), op. cit., p. 2). Transcribe el relato de la translación PUJOL TUBAU, Pere, Obra completa, Andorra, 1984, pp. 416-417.

53 A partir de 1378 se trasladó al día 7 de julio, con tal de no interrumpir las celebraciones de san Pedro y san Pablo.

54 Los textos litúrgicos del siglo XVI relatan que los cuerpos de los dos santos se sacaban en procesión, así como la ya citada translación del altar de san Ot a la cabecera de la catedral (ver nota 50).

55 VILlANUEVA, Jaime, Viaje literario á las iglesias de España, vol. XI, Madrid, Imprenta Real, 1850 , p. 42 .

56 Sant Ermengol bisbe Urgell (1010-1035). Història, Art, culte i devocions. Seu d'Urgell, Bisbat d'Urgell, 2010; BARAUT, Cebrià, "Les fonts documentals i hagiográfiques medievals de la vida i miracles de sant Ermengol, bisbe d'Urgell (1010-1035)", en Urgellia, n 14, 1998-2001, pp. 137-165. 


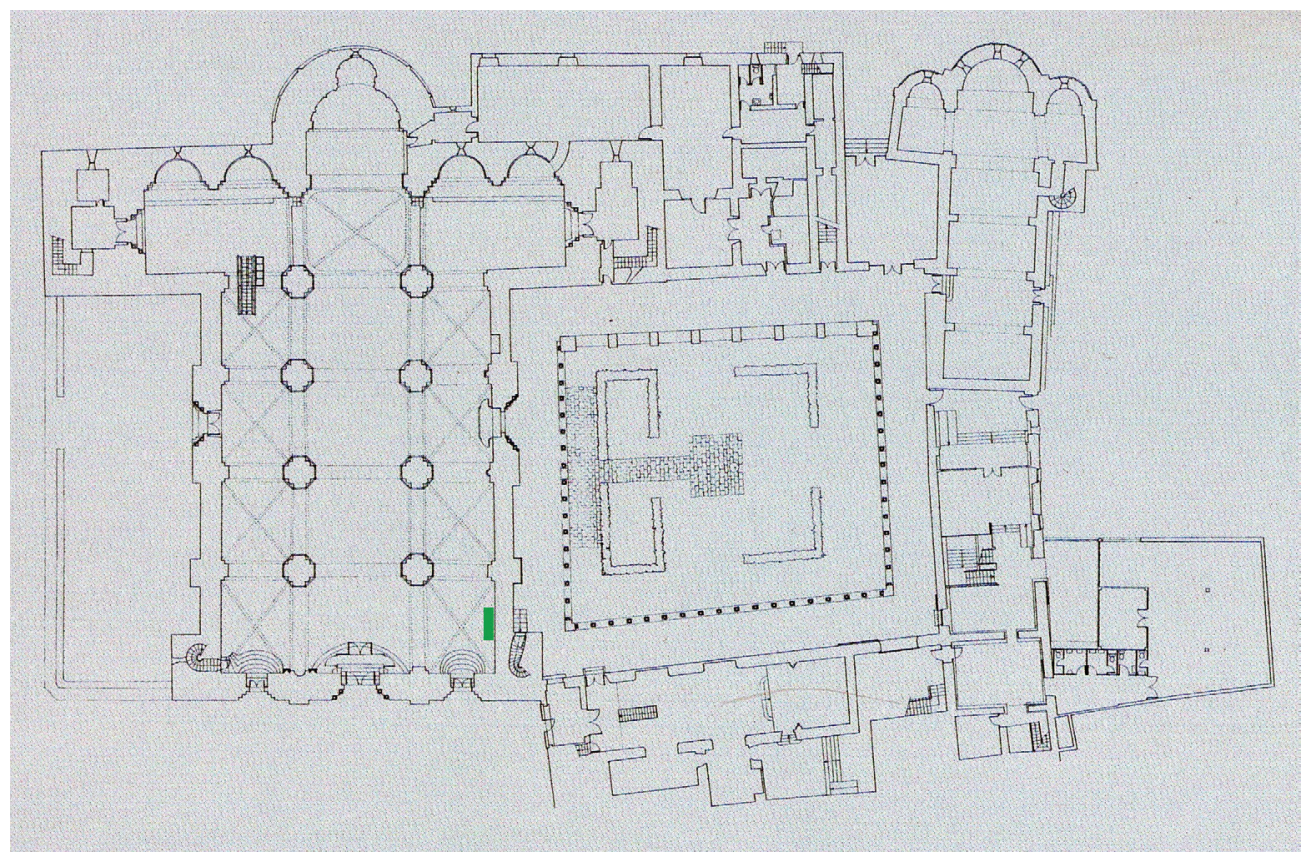

Fig. 4. Ubicación del altar de san Ot en la catedral de Santa María de la Seu d’Urgell hasta su translación en el siglo XVI.

de Roda-Barbastro por el rey Alfonso I de Aragón. Los conflictos por los dominios territoriales de ambos centros episcopales desembocaron en la canonización de los dos obispos con fechas muy cercanas, mostrando así la creciente importancia de sus respectivas sedes ${ }^{57}$. San Ramón y san Ot comparten el hecho de conservar objetos vinculados con su ajuar, como la fragmentaria cátedra de san Ramón o la dalmática, parte de las vestiduras episcopales con las que se enterraría al obispo ${ }^{58}$.

\section{El ajuar del santo obispo, ornamenta ecclesiae para la catedral}

Por lo tratado hasta ahora, cabe imaginar que en el año 1133, con motivo de la ceremonia de la canonización de san Ot, se prepararía un acto con la dignidad que el santo obispo de Urgell se merecía. Tanto la importancia de este suceso como los dos testigos bordados que han llegado hasta nuestros días, nos hacen pensar en que se

57 BLASCO DE LANUZA, Vincencio, Historias ecclesiasticas y secvlares de Aragon, Zaragoza, Iuan de Lanaia y Qvartanet, 1622, pp. 458-459.

58 PARTEARROYO LACABA, Cristina, "Dalmática de San Ramón del Monte, en Roda de Isábena", en Obras maestras recuperadas, Madrid, 1998, pp. 78-80. Para un estudio de la figura de san Ramón de Roda y su canonización, vid. ESPAÑOL BERTRÁN, Francesca, "Le sépulcre de sant Ramon de Roda. Utilisation liturgique du Corps Saint”, en Les Cahiers de Saint-Michel de Cuxa, vol. XXIX, 1998, pp. 177-187. 
debieron preparar ex profeso algunos ornamenta ecclesiae con tal de engalanar el espacio catedralicio. Este no fue un hecho aislado, puesto que es bien conocido que para ceremonias de este rango se realizaban objetos expresamente. En el mundo del textil cabe recordar el bordado conocido como Sternenmantel o Manto de las estrellas (Tesoro de la catedral de Bamberg) del emperador Enrique II (1002-0122), una capa de ceremonia que debió utilizar en su coronación del año 1014 en Roma ${ }^{59}$. O también el Tapiz de la Creación, que pudo haber decorado la catedral de Girona en el concilio allí celebrado el año 1097 y ser utilizado en ceremonias litúrgicas pascuales ${ }^{60}$. Aunque no podamos saber como era el sepulcro donde se albergaba el cuerpo de san Ot en aquel preciso momento ${ }^{61}$, sí podemos tener cierta idea de cómo debían ser los tejidos con los cuales proponemos que se decoraría el altar en esta ceremonia y, a posteriori, en otras festividades litúrgicas concretas. Teniendo en cuenta que la muerte del obispo era reciente y que su función primordial fue la defensa del Dogma, ¿qué mejor que incorporar a la parafernalia de esta solemne ceremonia imágenes icónicas que representasen el poder de Cristo Omnipotente y la celebración de la Maiestas Domini junto con su corte apostólica? Así, el estandarte de sant Ot pudo colgar sobre el sepulcro del santo obispo mientras que el frontal complementaría su figuración desde la parte delantera del altar donde se celebraban las misas en el contexto de la catedral ${ }^{62}$. De esta manera, ambos reproducían una imagen mayestática, a la vez que el pendón transmitía el contundente mensaje de la Resurrección de Cristo y el frontal glosaría esta representación con otros significados. Por ejemplo, con la representación simbólica de la Creación, el Bautismo y la Evangelización mediante las personificaciones de los ríos de Paraíso, y también con distintas lecturas de la obra evangelizadora de los Apóstoles, ejemplo que siguió fielmente el obispo. La referencia directa del frontal a las cruces gemadas, también símbolo de la Resurrección, nos hace pensar en una función relacionada con el culto funerario. Esta se apoyaría por la presencia de la inscripción VIA VERITAS, que remite al triunfo de Cristo sobre la muerte. La victoria sobre la muerte y su mensaje evangelizador son precisamente los elementos que relacionan estas imágenes con la devoción de los santos y, concretamente, con el culto de san Ot.

A modo de conclusión, proponemos el monasterio de Santa Cecília d'Elins como posible centro de producción local de bordados, en relación a la cercana catedral de la Seu d'Urgell y a la casa condal de Urgell. Fruto de estos posibles nexos, podríamos conservar parte de lo que podría haber sido el ajuar del obispo Ot, es decir, el estan-

59 DODWELL, Charles. R., Artes pictóricas en Occidente, 800-1200, Madrid, 1995, pp. 59-61; O'CONNOR, E. C. W., The Star Mantle of Henry II, University Microfilms International, Ph. D, Ann Arbor, 1980; GUNDEL, H. G., Zodiacos. Tierkreisbilder im Altertum. Kosmische Bezüge und Jenseitsvortellungen im antiken Alltagsleben, Maguncia, 1992, p. 315 n. 406.

60 CASTIÑEIRAS GONZÁLEZ, Manuel (2011), op. cit., p. 12.

61 El arca actual es posterior, como ya describe VILLANUEVA, Jaime (1850), op. cit., p. 40: "Debió destruirse el arca donde primero fue depositado con motivo de trasladarse sus huesos á la que hoy tiene de plata en el primer altar del crucero á la parte de la epístola, que es de pésimo gusto".

62 La absoluta ausencia de menciones a ambos bordados en la documentación catedralicia sugiere que, más que tratarse de dos objetos vinculados físicamente al lugar físico de un altar, deban relacionarse con un uso especialmente limitado a ceremonias del calendario litúrgico como ya se ha mencionado. 
darte y el frontal. Estas dos obras, por otra parte tradicionalmente relacionados con la figura del santo obispo ${ }^{63}$, son excepcionales dentro del románico catalán y peninsular. La conservación de este tipo de obras nos deja imaginar que debieron existir paralelos en otros centros episcopales que engalanarían estos espacios en sus ceremonias más fastuosas.

63 Igual que ocurre con la ya citada estola de san Narcís de Sant Feliu de Girona, pieza vinculada con la tumba del santo venerado en el lugar. 